\title{
BENTUK DAN MAKNA ENDE JEIR PADA MASYARAKAT MANDAILING DI KELURAHAN WEK V PADANGSIDIMPUAN
}

\author{
LAURI NOVITA SINAGA \\ PENDIDIKAN MUSIK
}

\begin{abstract}
Lauri Novita Sinaga. NIM 2131140024. Forms And Meaning Of Ende Jeir In The Mandailing Society In Wek V Village Padangsidimpuan. Faculty of Language and Art. State University of Medan 2017.

This study aims to determine the form and significance of the Ende Jeir in the Mandailing Society in Kelurahan Wek V Padangsidimpuan. The purpose of this research is to find out the form of Ende Jeir song in Mandailing community in Wek V Padangsidimpuan Village, to know the meaning contained in Ende Jeir in Mandailing community in Wek V Padangsidimpuan Village, to know the function of Ende Jeir in Mandailing community in Wek V Village Padangsidimpuan, to know the response of local people to preserve Ende Jeir on Mandailing community in Wek V Padangsidimpuan Village.
\end{abstract}

The theory used is form, meaning, function, and Ende. The shape is the arrangement of the frame of a song that is determined according to the parts of the sentence. Meaning is the purpose that is derived from things that want to be shown by something or want to be expressed, exposed, with the word actually does not interfere with the value of taste. The function of music is to express the taste, and simultaneously as an activity of various types of human communication. Ende is a traditional song (folksong), which represents the representation of structure, function and cultural values.

Methods in this research using qualitative descriptive method. The samples in this study were the lecture and audio visuals of Ende Jeir, singer Ende Jeir, artist and community Wek V Padangsidimpuan Village. This data collection is done by observation method or observation, interview, and documentation. This research was taken at Kelurahan Wek V Padangsidimpuan, and this research was conducted from August 2017.

The results of this study indicate that the form of Ende Jeir song consists of a one part song form, with AA 'form. the meaning of Ende Jeir is a prayer, plea, expectation of parents to his daughter who is doing this marriage and singing to advise on a good domestic life. Ende Jeir function is as symbolic representation media, media of emotional expression and media of cultural preservation. Ende Jeir needs to be preserved because it begins to be forgotten and left behind. For that, it needs to be developed and introduced in the young generation so as not to just disappear.

Keyword: Form, Meaning, Ende Jeir 


\section{PENDAHULUAN}

\section{A. Latar Belakang}

Keanekaragaman bangsa Indonesia ditandai dengan adat istiadatnya masing-masing sesuai dengan kebudayaan yang dilaksanakan kaumnya. Kebudayaan di setiap daerah sangat berpengaruh dalam pola pikir dan kebiasaan masyarakat. Setiap daerah mempunyai ciri khas dan kebiasaan tersendiri dalam kelompok masyarakat tersebut.

Mandailing merupakan salah satu suku yang berada di daerah Kabupaten Tapanuli Selatan. Ibu Kota dari Kabupaten Tapanuli Selatan adalah Sipirok. Di sebelah Utara, kabupaten ini berbatasan dengan Kabupaten Tapanuli Tengah dan Tapanuli Utara Di bagian Timur, berbatasan dengan Padang Lawas dan Padang Lawas Utara, sebelah Barat dan Selatan berbatasan dengan Kabupaten Mandailing, dan tepat di tengah wilayahnya terdapat kota
Padangsidimpuan yang seluruhnya dikelilingi oleh kabupaten ini.

Masyarakat Mandailing memiliki berbagai nyanyian tradisional (folksongs) yang disebut sebagai "ende", dimana salah satunya adalah Ende Jeir. Ende Jeir mengisahkan tentang riwayat suatu marga, atau nasihat tentang kehidupan perkawinan, atau tentang kekerabatan yang sangat dekat yang disebut kaum na solkot.

Perubahan dalam kebudayaan yang termasuk perubahan dalam kesenian merupakan hal yang sewajarnya dan terus berlaku sesuai dengan proses dinamika yang dialami masyarakat pendukungnya. Dengan berkembangnya ilmu pengetahuan dan teknologi yang sangat pesat, nyanyian-nyanyian tradisional semakin jarang dijumpai dalam adat-istiadat, khususnya masyarakat Mandailing. Hal ini juga terjadi pada ende jeir yang semakin jarang dijumpai bahkan sama sekali 
tidak digunakan lagi saat upacara adat "horja siriaon" sampai sekarang ini dikarenakan keterbatasan parjeir (yang menyanyikan ende jeir) dan tokoh adat maupun penatua masyarakat dalam cara menyampaikan pesan/nasihat kepada pengantin maupun keluarga dekat dilakukan dengan cara penyampaian lisan seperti layaknya berbicara seharihari.

Berdasarkan uraian di atas, penulis tertarik untuk meneliti tentang "Bentuk Lagu dan Makna Ende Jeir Pada Masyarakat Mandailing di Kelurahan Wek V Padangsidimpuan”. Penelitian ini merupakan salah satu upaya untuk menjaga dan melestarikan salah satu lagu rakyat Mandailing.

\section{B. Tujuan}

1. Untuk mengetahui bentuk lagu Ende Jeir pada masyarakat Mandailing di Kelurahan Wek V Padangsidimpuan.

2. Untuk mengetahui makna yang terkandung dalam Ende Jeir pada masyarakat Mandailing di Kelurahan Wek V Padangsidimpuan.
3. Untuk mengetahui fungsi Ende Jeir pada masyarakat Mandailing di Kelurahan Wek V Padangsidimpuan.

4. Untuk mengetahui tanggapan masyarakat setempat dalam melestarikan Ende Jeir pada masyarakat Mandailing di Kelurahan Wek V Padangsidimpuan.

\section{Teori Yang Digunakan}

1. Teori Bentuk

Teori bentuk yang digunakan yaitu menurut teori Prier (2004:2) yang mengemukakan bahwa:

Bentuk musik merupakan suatu gagasan/ ide yang nampak dalam pengelolaan/ susunan semua unsur musik dalam sebuah komposisi (melodi, irama, harmoni, dan dinamika). Ide ini mempersatukan nada-nada musik serta terutama bagian-bagian komposisi yang dibunyikan satu persatu sebagai kerangka. Bentuk musik dapat dilihat juga secara praktis: sebagai 'wadah' yang 'di 
isi' oleh seorang komponis dan

diolah sedemikian hingga

menjadi musik yang hidup.

\section{Teori Makna}

Teori makna yang digunakan yaitu menurut teori Marcel Danesi (2004:7) menyatakan bahwa: "Semiotika adalah ilmu tentang tanda dan kode-kodenya serta penggunaannya dalam masyarakat".

\section{Teori Fungsi}

Teori fungsi yang digunakan ada 3 fungsi yaitu menurut teori Moh. Muttaqim Kustap (2003:23) :

\section{a. Fungsi Ekspresi Emosional}

Disini musik berfungsi sebagai media bagi seseorang untuk mengungkapkan perasaan atau emosinya. Dengan kata lain si pemain dapat mengungkapkan perasaan atau emosinya melalui musik. Para pencipta musik dari waktu ke waktu telah menunjukkan kebebasannya mengungkapkan ekspresi emosinya yang dikaitkan dengan berbagai objek serapan seperti alam, cinta, suka-duka, amarah, pikiran dan bahkan dengan cara mengotak-atik nada-nada sesuai dengan suasana hatinya.

b. Fungsi Representasi Simbolik Musik memiliki fungsi dalam melambangkan suatu hal. Hal ini dapat dilihat dari aspek-aspek musik tersebut, misalnya tempo sebuah musik. Jika tempo sebuah musik lambat, maka kebanyakan teksnya menceritakan halhal yang menyedihkan. Sehingga musik itu melambangkan akan kesedihan. Dalam berbagai budaya bangsa, sukusuku atau daerah-daerah yang masih mempertahankan tradisi nenek moyang mereka; musik digunakan sebagai sarana mewujudkan simbol-simbol dari niai-nilai tradisi dan budaya setempat. Kesenangan, kesedihan, kesetiaan, kepatuhan, penghormatan, rasa bangga, rasa memiliki atau perasaan-perasaan khas mereka disimbolkan melalui musik baik secara sendiri maupun menjadi bagian dari tarian, syair-syair, dan upacara-upacara.

c. Fungsi Pelestari Kebudayaan Musik berfungsi dalam melestarikan kebudayaan yang secara 
turun temurun sudah diperkenalkan. Tema-tema dan cerita di dalam syair menggambarkan budaya secara jelas. Syair-syair lagu juga berasal dari pantun-pantun yang biasa dilantunkan oleh masyarakat adat dan daerah-daerah di Indonesia.

\section{Teori Ende}

Teori Ende yang digunakan yaitu menurut teori Nasution (2013:1), ende adalah "nyanyian tradisional" (folksong). Ende menampilkan representasi struktur, fungsi, dan nilainilai yang sebagian masih berlaku dan dijunjung tinggi oleh masyarakat Mandailing sampai sekarang.

Masyarakat Mandailing memiliki berbagai corak nyanyian tradisional (folksongs) dan mereka menyebutnya sebagai ende yang dapat dibagi berdasarkan fungsi dan tujuan lagu yang dilihat melalui isi liriknya. Adapun jenis-jenis ende itu adalah sebagai berikut:
1. Ende

Ungut-ungut, merupakan nyanyian yang mengisahkan tentang kesedihan, kerinduan, atau kepergian. Ungut-ungut (marungut-ungut) umumnya dilakukan oleh kaum pria berusia muda maupun tua.

2. Ende Jengjeng, merupakan tradisi nyanyian yang hampir sama dengan ungut-ungut, yang membedakan adalah terletak pada gaya nyanyian yang dibawakan.

3. Ende Jeir, merupakan tradisi nyanyian yang mengisahkan tentang riwayat sebuah marga, atau nasehat tentang kehidupan perkawinan, atau tentang kekerabatan yang dekat.

4. Ende Ile-ile, merupakan nyanyian di malam hari ketika bulan purnama. Dilakukan di halaman ataupun dipelataran, tua muda semua bergembira menikmati kurnia cahaya rembulan. 
mengisahkan ungkapan

kekecewaan dan pelepas rindu kepada orang yang dikasihinya. Onang-onang lama-lama berkembang, berfungsi sebagai ungkapan rasa sukacita (kegembiraan seseorang).

6. Ende Sitogol, merupakan nyanyian yang berisi keluhkesah (ungkapan perasaan) tentang cinta atau pun kemelaratan.

7. Ende Bue-bue, merupakan tradisi nyanyian untuk menidurkan anak. Biasanya dilakukan oleh para ibu ketika akan menidurkan anaknya.

8. Ende Uro-uro, merupakan nyanyian ketika seorang ayah mengungkapkan rasa iba lewat nyanyian kepada anaknya yang ditinggal mati oleh ibunya.

9. Ende Mamuro, merupakan nyanyian seorang petani yang menghalau silopak

\section{Metode Penelitian}

1. Metode penelitian yang digunakan yaitu deskriptif kualitatif.

2. Populasi/Sampel

Populasi dalam penelitian ini dibagi yaitu keseluruhan ende yang ada pada masyarakat Mandailing berkisar 9 ende dan masyarakat Mandailing yang berdomisili di Kelurahan Wek V Padangsidimpuan berkisar 300 kk (kepala keluarga). Sampel dalam penelitian ini adalah partitur dan audio visual Ende Jeir, penyanyi satu orang, seniman dua orang, dan masyarakat Kelurahan Wek V lima belas orang.

3. Waktu/Lokasi Penelitian

Waktu penelitian 3 bulan. Lokasi penelitian di Kelurahan Wek V Padangsidimpuan.

4. Teknik Pengumpulan Data Teknik pengumpulan data yang digunakan yaitu: Observasi, 
wawancara, dokumentasi dan

studi kepustakaan.

5. Teknik Analisa Data

Penelitian ini menggunakan teknik analisis data kualitatif yang terkumpul melalui observasi dan wawancara untuk memperlihatkan situasi, kondisi, dan suasana masyarakat Mandailing dalam mengapresiasikan Ende Jeir di Kelurahan Wek V Padangsidimpuan.

ISI

2 37

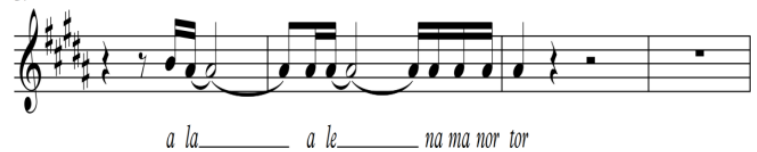

\section{Bentuk Lagu Ende Jeir} ENDE JEIR
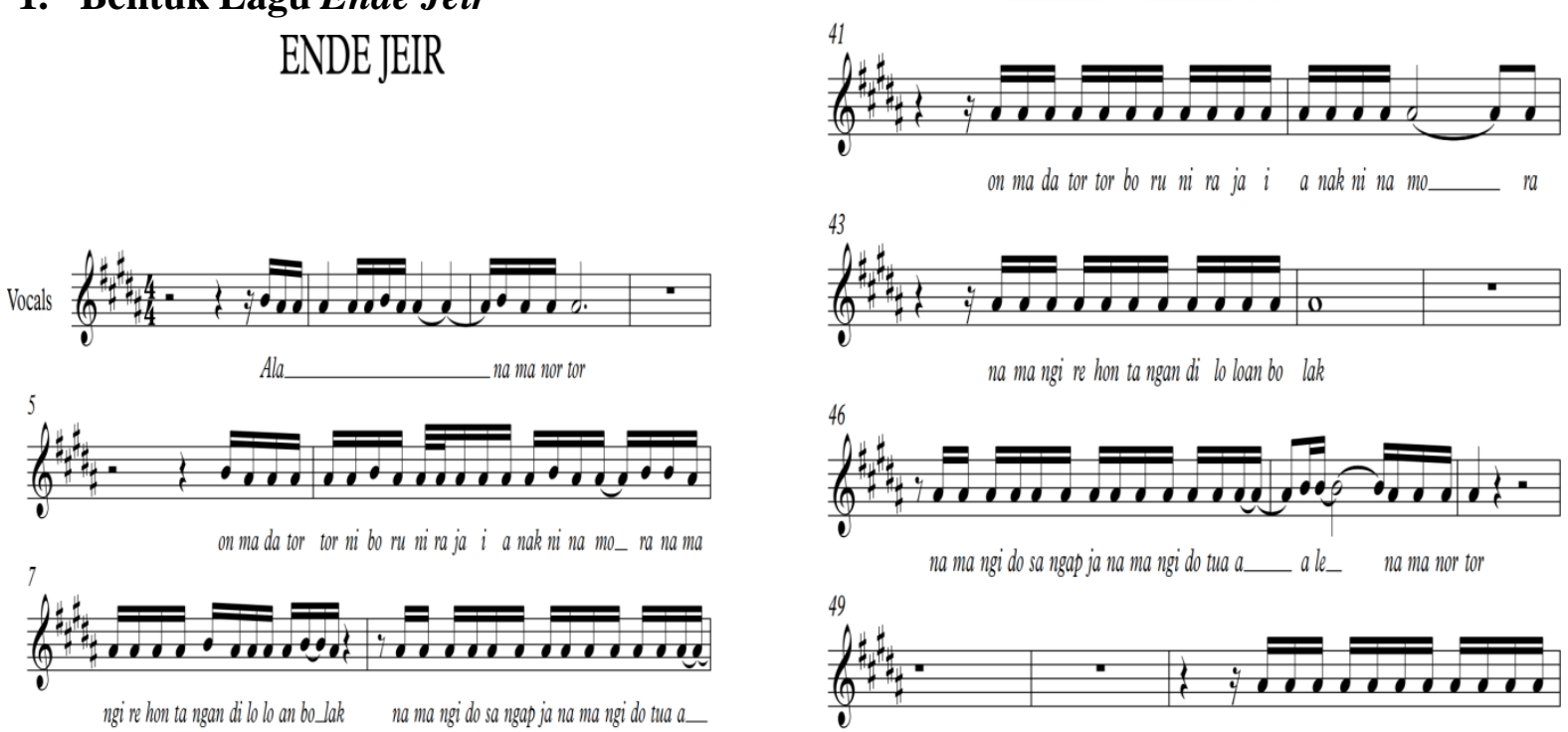
ngi re hon ta ngan di lo lo an bo lak na ma ni do sa ngap ja na ma noi do tua a

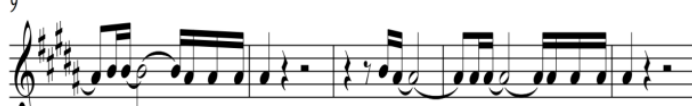
_ale_ namanortor_ ala__ale__namanor tor

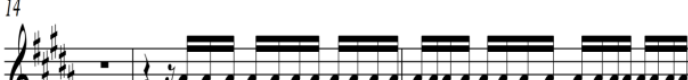

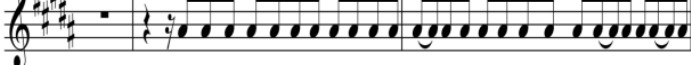
on ma da tor tor ni bo ru ni na di lu_at ni ta no pa kan tan tu_a on_ a

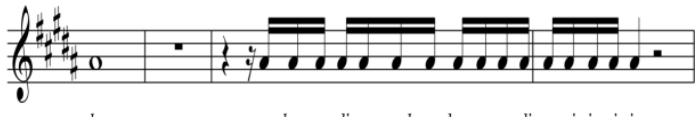

le ang kon ton di ma rarak ara hon so ton di ma ri ring i ring 21

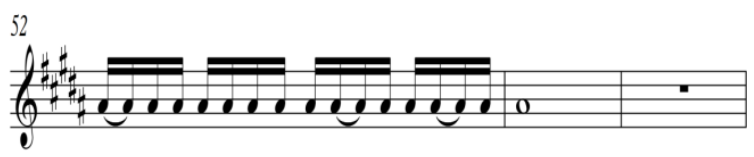

li__ at mi ta no pakantantu_a on___ a le 55

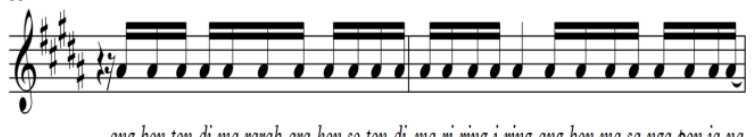
ang kon ton di ma rarak ara hon so ton di ma ri ring $i$ ring ang kon ma sa nga pon ja na 

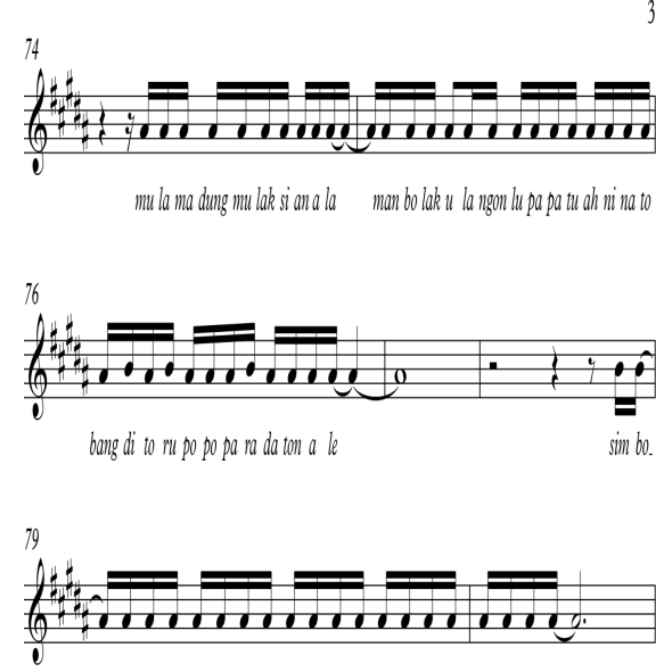

- ra di ngindi nginso sim bo ra di ba tur nir ja la ja la a le
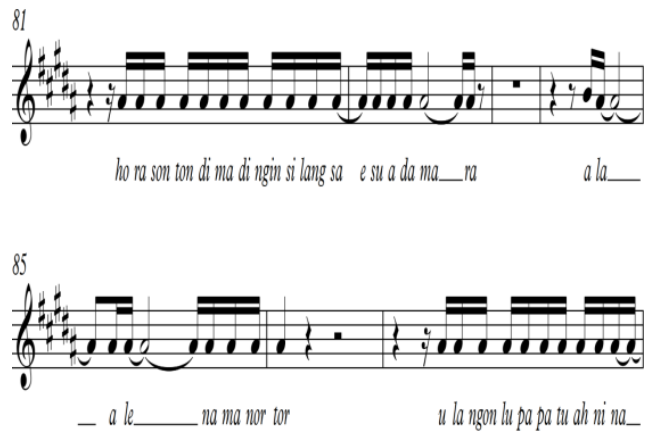

a. Motif

Ende jeir menggunakan birama 4/4 dengan nada dasar $B=$ do. Pada lagu ini banyak terjadi pengulangan hanya saja syairnya yang berubahubah. Pada birama pertama sampai birama kedua adalah sebagai $\mathrm{m} 1$ (motif asli).

b. Frase

Frase terdiri dari frase pertanyaan dan frase jawaban.

\begin{tabular}{|c|c|}
\hline Frase & Birama 1 sampai \\
Pertanyaan & birama 3 \\
& Birama 9 sampai \\
& birama 13 \\
\hline
\end{tabular}

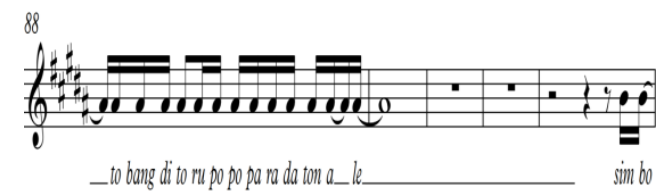




\begin{tabular}{|c|c|}
\hline & $\begin{array}{c}\text { Birama } 25 \text { sampai } \\
\text { birama } 27 \\
\text { Birama } 37 \text { sampai } \\
\text { birama } 39 \\
\text { Birama } 49 \text { sampai } \\
\text { birama } 51 \\
\text { Birama } 58 \text { sampai } \\
\text { birama } 60 \\
\text { Birama } 69 \text { sampai } \\
\text { birama } 71 \\
\text { Birama } 84 \text { sampai } \\
\text { birama } 86 \\
\text { Birama } 92 \text { sampai } \\
\text { birama } 94\end{array}$ \\
\hline $\begin{array}{c}\text { Frase } \\
\text { Jawaban }\end{array}$ & $\begin{array}{c}\text { Birama } 5 \text { sampai } \\
\text { birama } 8 \\
\text { Birama } 15 \text { sampai } \\
\text { birama } 23 \\
\text { Birama } 29 \text { sampai } \\
\text { birama } 35 \\
\text { Birama } 41 \text { sampai } \\
\text { birama } 38 \\
\text { Birama } 62 \text { sampai } \\
\text { birama } 67 \\
\text { Birama } 74 \text { sampai } \\
\text { birama } 77 \\
\text { Birama } 81 \text { sampai } \\
\text { birama } 82 \\
\text { Birama } 95 \text { sampai }\end{array}$ \\
\hline
\end{tabular}

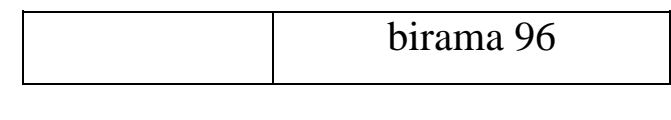

c. Kalimat

Kalimat terdiri dari frase pertanyaan dan frase jawaban. Dimulai dari birama 1 sampai birama 23. Ini disebut sebagai bagian A. Kalimat A' terdiri dari frase pertanyaan dan frase jawaban, dimulai dari birama 25 sampai birama 35. Pengulangan terdapat pada birama 37 sampai birama 48 , birama 51 sampai birama 60, dan birama 69 sampai birama 96.

\section{Makna lagu Ende Jeir}

Makna yang terkandung dalam Ende Jeir pada masyarakat Mandailing ini adalah tentang permohonan atau ungkapan isi hati orang tua kepada boru (anak perempuan) yang akan melangsungkan perkawinan agar di kehidupan perkawinannya diberikan berkat dari Yang Maha Kuasa, diberikan keturunan yang banyak, dan menjadi keluarga yang disegani di masyarakat. Ende jeir inilah yang menceritakan harapan orang tua 
kepada anak perempuannya saat sudah tidak tinggal bersama dengan mereka lagi, dan agar anak perempuannya tidak lupa kepada orang tua yang telah merawat dan membesarkannya sampai pada masa dimana anak tersebut melepas masa lajangnya kepada masa untuk memulai sebuah rumah tangga yang baru.

\section{Fungsi Ende Jeir}

a. Sebagai Media Ekspresi Emosional

Ende jeir adalah media untuk mengungkapkan doa, permohonan maupun nasehat orang tua kepada anak perempuannya yang akan memulai rumah tangga baru, yang dituangkan ke dalam lagu. Isi lagunya bebas diucapkan dan di ekspresikan sesuai dengan yang ada dalam hati dan pikiran orang tua. Pada lagu ini orang tua berharap anaknya saat memulai kehidupan rumah tangga nanti menjadi keluarga yang bahagia dan agar kehidupan rumah tangganya jauh lebih baik dari orang tuanya.

b. Sebagai Representasi Simbolik Lagu Ende jeir melambangkan perasaan hati orang tua yang akan melepaskan anak perempuan yang telah dibesarkan bertahun-tahun lamanya dan pergi kepada keluarga lain. Karena ende jeir ini merupakan ungkapan permohonan dan nasehat orang tua yang terdalam kepada anak perempuannya, tidak sedikit orang tua bahkan anaknya akan menangis saat mendengar lagu ini dinyanyikan dalam upacara adat perkawinan masyarakat Mandailing.

c. Sebagai Media Pelestari Kebudayaan

Ende jeir sebagai salah satu warisan leluhur Mandailing 
yang harus tetap dijaga keberadaannya, dipergunakan dalam upacara adat perkawinan (horja siriaon) dan harus tetap diperkenalkan kepada setiap generasinya agar mereka juga berperan dalam melestarikan budaya Mandailing sehingga mengurangi angka kepunahan warisan leluhur dahulu.

\section{Tanggapan Masyarakat}

\section{Setempat dalam melestarikan}

\section{Ende Jeir}

Tanggapan masyarakat setempat dalam melestarikan Ende Jeir berbeda-beda. Ada yang ingin mempertahankan Ende Jeir tersebut dan ada juga yang tidak ingin melestarikannya. Lurah Wek V Firman Nasution (19 Agustus 2017), yang mengatakan bahwa Ende Jeir sangat perlu untuk dilestarikan. Untuk itu sangat perlu untuk melestarikan lagu Ende Jeir ini dengan memperkenalkan kembali Ende Jeir kepada generasi muda dan tetap menyanyikan Ende Jeir dalam upacara adat perkawinan masyarakat Mandailing.

\section{PENUTUP}

\section{Kesimpulan}

1. Bentuk lagu dari Ende Jeir adalah bentuk lagu satu bagian yaitu A-A'. Bentuk A terdiri dari frase pertanyaan dan frase jawaban yang terdapat pada birama 1 sampai birama 23. Bentuk A' terdiri dari frase pertanyaan dan frase jawaban yang terdapat pada birama 25 sampai birama 35. Pada lagu ini banyak terdapat pengulangan pada melodinya sedangkan syair/kalimat berubah-ubah 
sesuai dengan suasana hati yang menyanyikannya.

2. Makna yang terkandung pada Ende Jeir adalah makna permohonan dan nasehat orang tua kepada anak perempuannya yang melangsungkan perkawinan. Bagi kehidupan masyarakat Mandailing lagu ini adalah suatu wadah yang menggambarkan bagaimana dalamnya rasa sayang orang tua kepada anak perempuannya agar kelak anaknya bisa menjadi istri dalam keluarga yang membawa kebahagiaan, disegani masyarakat, dan memiliki keturunan yang banyak.

3. Fungsi Ende Jeir ini adalah nyanyian yang mengungkapkan permohonan dan nasehat orang tua kepada anak perempuan yang melangsungkan perkawinan dan bersifat sebagai media ekspresi emosional. Lagu ini juga sebagai sarana untuk menyampaikan rasa sayang orang tua kepada anak perempuannya sekaligus sebagai doa kepada Yang Maha Esa agar kelak anaknya menjadi keluarga yang bahagia. Selain itu juga sebagai media representasi simbolik dan sebagai pelestari kebudayaan.

\section{DAFTAR PUSTAKA}

Danandjaja, James. 1997. Folklore Indonesia, Ilmu, Gosip, Dongeng dan Lain- lain. Jakarta: Gramedia.

Danesi, Marcel. 2004. Pesan, Tanda, dan Makna. Yogyakarta : Jalasutra

Kustap, Moh. Muttaqim. 2003. Seni Musik Klasik. Jakarta: Depdikbud

Nasution, Edi. 2013. Eksistensi "Ende" dan "Ende-ende" dalam Masyarakat Medan. Mandailing. Karya Ilmiah.

Prier, Sj. 2004. Ilmu Bentuk Musik. Yogyakarta : Pusat Musik Liturgi.

Rosdakarya. 
(Sumber:http://gondang.blogspot.com/2 013/03/ende-ende-ende.html, $6 \mathrm{Mei}$ 2017)

(Sumber:http://pamantulis.blogspot.co.i d/p/seni-musik.html2016, 4 Juni 2017) 